Article

\title{
Condensed Tannins from Mangrove Species Kandelia candel and Rhizophora mangle and Their Antioxidant Activity
}

\section{Liang-Liang Zhang ${ }^{1,2}$, Yi-Ming Lin ${ }^{1, *}$, Hai-Chao Zhou ${ }^{1}$, Shu-Dong Wei ${ }^{1}$ and Jia-Hong Chen ${ }^{2}$}

1 Key Laboratory of the Ministry of Education for Coastal and Wetland Ecosystems, School of Life Sciences, Xiamen University, Xiamen 361005, China

2 Key and Open Lab. on Forest Chemical Engineering SFA, Institute of Chemical Industry of Forest Products, CAF; Nanjing 210042, China

* Author to whom correspondence should be addressed; E-Mail: linym@xmu.edu.cn; Tel.: +865922187657.

Received: 12 December 2009; in revised form: 12 January 2010 / Accepted: 17 January 2010 / Published: 20 January 2010

\begin{abstract}
The structures of condensed tannins isolated from two mangrove species, Kandelia candel and Rhizophora mangle, were characterized by ${ }^{13} \mathrm{C}$ nuclear magnetic resonance (NMR) spectroscopy and matrix assisted laser desorption/ionization time-offlight mass spectrometry (MALDI-TOF MS) analyses. Results demonstrate that large heterogeneity occurs in degree of polymerization, pattern of hydroxylation, and substitution with monosaccharides in the structures of the condensed tannins. Condensed tannin oligomers from $K$. candel and $R$. mangle were shown to be heterogeneous mixtures consisting of procyanidin and prodelphinidin structural units with the former dominating. The MALDI-TOF mass spectra contained masses corresponding to a distinct oligomeric series of glycosylated heteropolyflavan units. In addition, condensed tannins from two mangrove plants were screened for their potential antioxidant activities using 1,1-diphenyl2-picrylhydrazyl (DPPH) and ferric reducing antioxidant power (FRAP) model systems.
\end{abstract}

Keywords: mangrove; condensed tannins; free radical scavenging activity; reducing power 


\section{Introduction}

Condensed tannins comprise a group of polyhydroxyflavan-3-ol oligomers and polymers linked by carbon-carbon bonds between flavanol subunits [1]. The most common classes are the procyanidins, which are chains of catechin, epicatechin, and their gallic acid esters, and the prodelphinidins, which consist of gallocatechin, epigallocatechin, and their galloylated derivatives as the monomeric units [2]. The properties of condensed tannins depend on their structures in terms of monomer units, their mean degree of polymerization (DP) and the linkage-type between flavan-3-ol units with a considerable range of structural variation [3]. Condensed tannins have attracted great attention due to rapid growing evidence associating these compounds with a wide range of potential health benefits. Recently, it has been suggested that any potential health benefits attributed to these compounds may be affected by the degree of polymerization [4]. However, detailed information on the condensed tannin profiles present in most plants is currently lacking, especially with regard to the more complex oligomeric structures, and analysis of higher condensed tannins is not feasible, since the number of isomers increases with increasing degrees of polymerization.

In mangrove species, condensed tannins are abundant components (as high as $20 \%$ dry weight) which prevent damage from herbivores [5,6], but they also show a diversity of other biological activities of historic and potential importance to humans [7]. In addition to application in leather tanning, mangrove extracts have been used for diverse medicinal purposes and have a variety of antibacterial, antiherpetic and antihelminthic activities [8,9]. The extracts of some mangrove species indicated significant antioxidant activity $[10,11]$, and we supposed the active compounds responsible for antioxidant activity were tannins. The structures of the main monomers constituting the condensed tannins were identified, these being catechin, epicatechin, epigallocatechin, and epicatechin gallate [12]. However, different condensed tannins present different structures and different degrees of polymerization [13] and these are unknown in the case of mangrove condensed tannins.

Because of the complex structural diversity and related physiochemical properties, condensed tannins were considered to be the final frontier of flavonoid research [14], and unexplored condensed tannins from mangrove plants may be potential resources for novel bioactive compounds. This study was designed to separate and characterize condensed tannins from two mangrove species (Kandelia candel and Rhizophora mangle), and to investigate their antioxidant activities. The isolated condensed tannins were subjected to ${ }^{13} \mathrm{C}$-NMR spectroscopy and matrix assisted laser desorption/ionization timeof-flight mass spectrometry (MALDI-TOF MS), which allows the detection of molecules with high molecular masses (from several hundred to several thousand Daltons). Due to the gentle ionization, fragmentation of the macromolecule under research can be avoided. Meanwhile, the free radical scavenging capacities and ferric reducing power of condensed tannins from two mangrove species were also discussed.

\section{Results and Discussion}

\subsection{Content of total phenolics and extractable condensed tannins}

Total phenolics contents in the leaves of $K$. candel and $R$. mangle were $130.32 \pm 4.66 \mathrm{mg} / \mathrm{g}$ and $182.62 \pm 21.43 \mathrm{mg} / \mathrm{g}$, respectively (Table 1). Extractable condensed tannin contents in the leaves of $K$. 
candel and $R$. mangle were $106.35 \pm 21.16 \mathrm{mg} / \mathrm{g}$ and $219.27 \pm 63.11 \mathrm{mg} / \mathrm{g}$, respectively. Polyphenols are the major plant compounds with antioxidant activity. The results strongly suggest that phenolics are important components in these plants, and some of their pharmacological effects could be attributed to the presence of these valuable constituents.

Table 1. The contents of total phenolics (TP) and extractable condensed tannins (ECT) from K. candel and R. mangle.

\begin{tabular}{ccc}
\hline Samples & $\mathbf{T P}_{(\mathbf{m g} / \mathbf{g})^{\boldsymbol{a}}}$ & ECT $\mathbf{~ ( m g / g )}^{\boldsymbol{b}}$ \\
\hline K. candel & $130.32 \pm 4.66 \mathrm{~b}$ & $106.35 \pm 21.16 \mathrm{~b}$ \\
R. mangle & $182.62 \pm 21.43 \mathrm{a}$ & $219.27 \pm 63.11 \mathrm{a}$ \\
\hline
\end{tabular}

${ }^{a} \mathrm{TP}$ were expressed as tannic acid as the standard; ${ }^{b}$ ECT were expressed as purified mangrove condensed tannins as the standard. Data are presented as the mean \pm standard deviation $(n=3)$.

Means with different letters are significant differences at $P<0.05$ levels.

\section{2. ${ }^{13} \mathrm{C}-\mathrm{NMR}$ analysis}

The condensed tannins were analyzed by ${ }^{13} \mathrm{C}-\mathrm{NMR}$ spectroscopy, and the signal assignment was performed according to the method by Czochanska et al. [15]. The ${ }^{13} \mathrm{C}-\mathrm{NMR}$ spectrum (Figure 1) of the $K$. candel condensed tannins in acetone- $d_{6} / \mathrm{D}_{2} \mathrm{O}$ shows characteristic peaks consistent with those of condensed tannins with dominant procyanidin units and a minor amount of prodelphinidins. The structural diversity of the linkages (A and B type) and stereoisomers of catechin and epicatechin units is apparent from the spectrum. Specially, C5, C7, and C8a carbons of procyanidins appear at 150 to $160 \mathrm{ppm}$. Peaks at 145.2 and $145.3 \mathrm{ppm}$ belong to $\mathrm{C} 3^{\prime}$ and $\mathrm{C} 4^{\prime}$ of procyanidin units. The signals at 114.8, 115.3 and $118.1 \mathrm{ppm}$ are assignable to the $\mathrm{C}^{\prime}, \mathrm{C}^{\prime}$ and $\mathrm{C}^{\prime}$ of procyanidin units. A small amount of prodelphinidins is also detected as its $\mathrm{C}^{\prime}$ ' peak and appears at $131.2 \mathrm{ppm}$, overlapping with the chemical shifts of $\mathrm{C}^{\prime}$. The cluster of peaks between 95 and $100 \mathrm{ppm}$ is assigned to $\mathrm{C} 8$ and $\mathrm{C} 6$ of procyanidins, and the peaks between 104 and 108 ppm is assigned to $\mathrm{C}^{\prime}{ }^{\prime}$ and $\mathrm{C}^{\prime}{ }^{\prime}$ of prodelphinidins. The region between 70 and $90 \mathrm{ppm}$ is sensitive to the stereochemistry of the C-ring. The ratio of the 2,3-cis to 2,3-trans isomers could be determined through the distinct differences in their respective $\mathrm{C} 2$ chemical shifts. C2 gives a resonance at $75.7 \mathrm{ppm}$ for the cis form and $79 \mathrm{ppm}$ for the trans form. From the peak areas, it is estimated that the cis isomer is dominant. C3 of both cis and trans isomers occurs at $71 \sim 72 \mathrm{ppm}$. The peak at $64 \mathrm{ppm}$ is due to $\mathrm{C} 3$ of the terminal unit. The $\mathrm{C} 4$ atoms of the extension units showed a broad peak at 36 ppm, while the terminal $\mathrm{C} 4$ exhibits multiple lines at 29 and $27 \mathrm{ppm}$ [16]. In addition, the glycosides were also detected in the spectrum. The carbon signals at 101.8 ppm (C''1), 75 77 ppm (C'22, C'3 and C',5), 71 ppm (C',4), and 61 ppm (C',6) were in agreement with those of the glycosides [17]. The sugar moiety was supported by the result of a sugar analysis of the acidic hydrolysis of mangrove condensed tannins. The carbon signal at $71.8 \mathrm{ppm}$ (C3) suggested the glycose moiety to be connected to the $\mathrm{C} 3$ position. The ${ }^{13} \mathrm{C}-\mathrm{NMR}$ spectrum of condensed tannins from $R$. mangle was similar to that of $K$. candel. The typical signals due to procyanidin and prodelphinidin units with some glycosides were also found in $R$. mangle condensed tannins. 
Figure 1. ${ }^{13} \mathrm{C}-\mathrm{NMR}$ spectra $(150 \mathrm{MHz})$ of condensed tannins from $K$. candel and $R$. mangle; solvent, acetone- $d_{6} / \mathrm{D}_{2} \mathrm{O}$; room temperature. Identity of the structures: $\mathrm{R}_{1}=\mathrm{H}$, epicatechin; and $\mathrm{R}_{1}=\mathrm{OH}$, epigallocatechin.
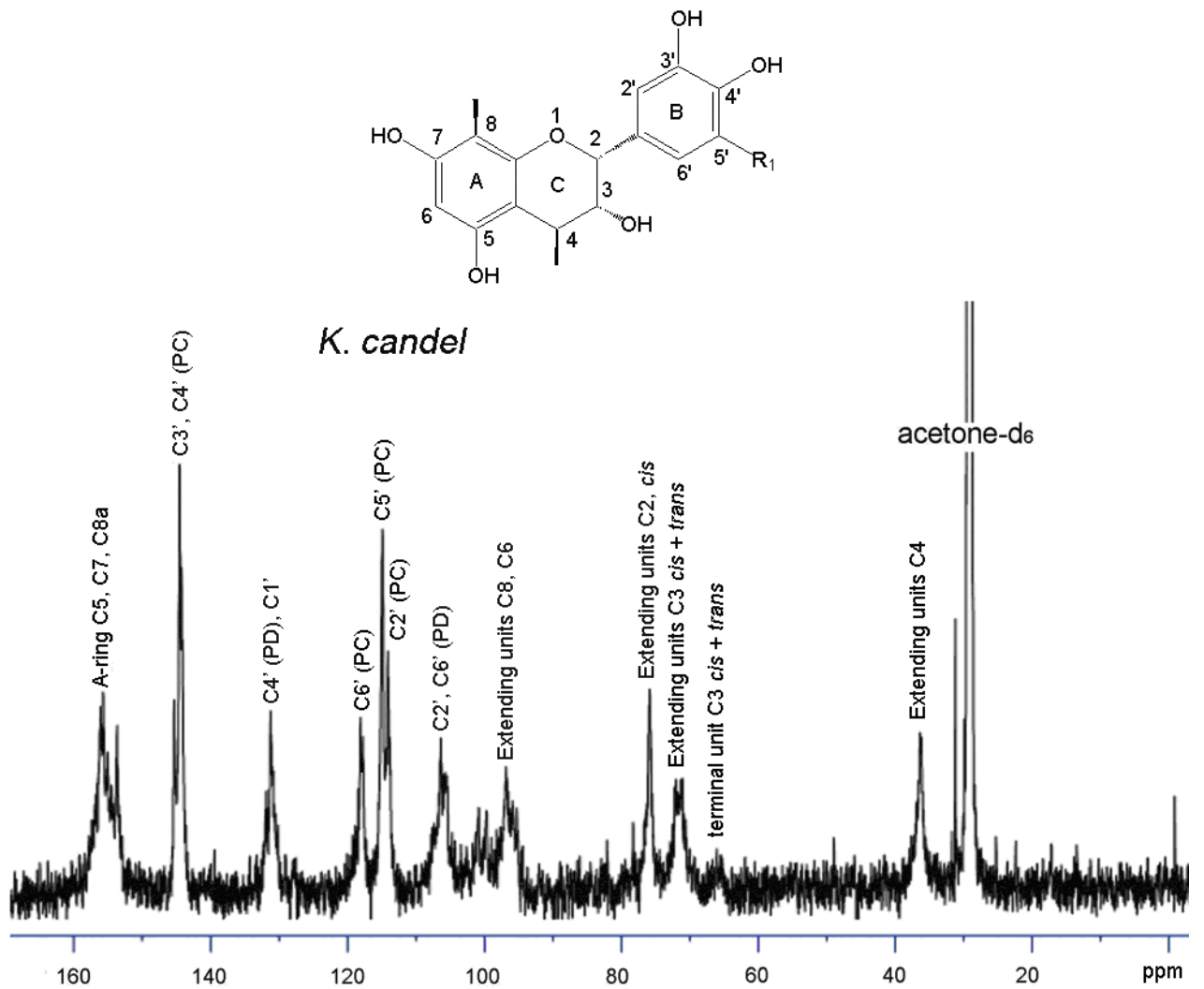

R. mangle

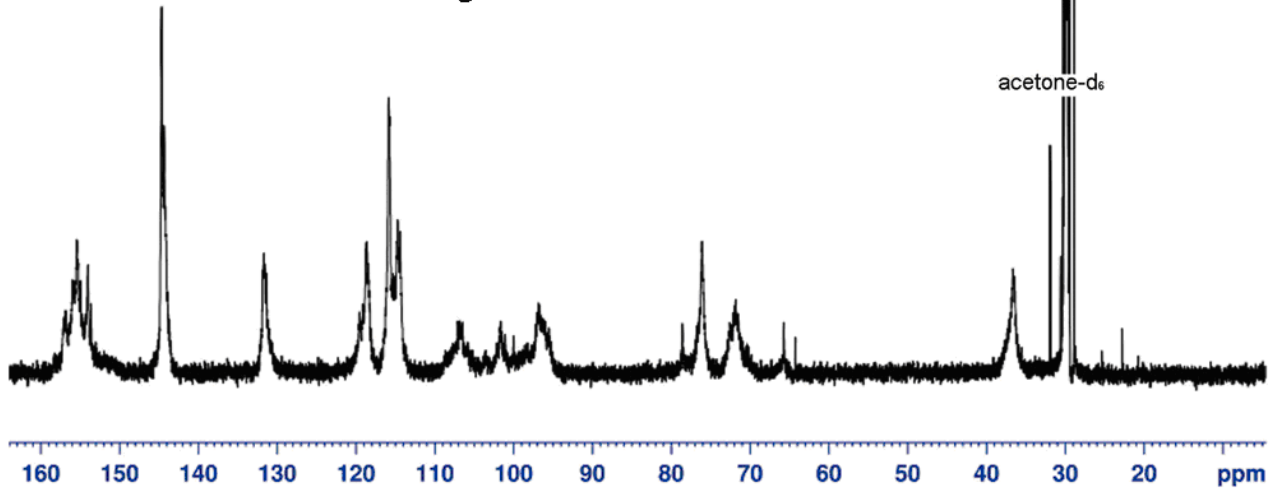

\subsection{MALDI-TOF MS analysis}

Although the ${ }^{13} \mathrm{C}$-NMR spectra revealed the complex structural characteristics of the mangrove condensed tannins, quantitative data regarding the degree of polymerization cannot be reliably obtained. Further characterization was achieved by MALDI-TOF mass spectrometry. Figure 2 shows the MALDI-TOF mass spectra of the condensed tannins isolated from $K$. candel and $R$. mangle leaves, recorded as $\mathrm{Cs}^{+}$adducts in the positive ion reflectron mode and showing a series of repeating procyanidin polymers. The polymeric character is reflected by the periodic peak series representing different chain lengths. The masses of the highest peaks among the polyflavonoid tannin polymers 
from mangrove species with identical DP increased at the distance of $288 \mathrm{Da}$, corresponding to one catechin/epicatechin monomer (Table 2). Therefore, prolongation of condensed tannins is due to the addition of catechin/epicatechin monomers. Condensed tannins with a DP of 2 to 11 $(\mathrm{m} / \mathrm{z} 711.33 \sim 3304.45)$ were detected in K. candel, and condensed tannins with a DP of 3 to 16 ( $\mathrm{m} / \mathrm{z}$ 999.34 4751.54) were detected in $R$. mangle. The spectra did not contain ions with 2 Da lower than that of the highest peaks among the polyflavan-3-ols polymers.

Figure 2. MALDI-TOF positive reflectron mode mass spectra of the condensed tannins from $K$. candel and $R$. mangle. Inset is an enlarged spectrum of masses representing a procyanidin series with varying hydroxylation patterns.

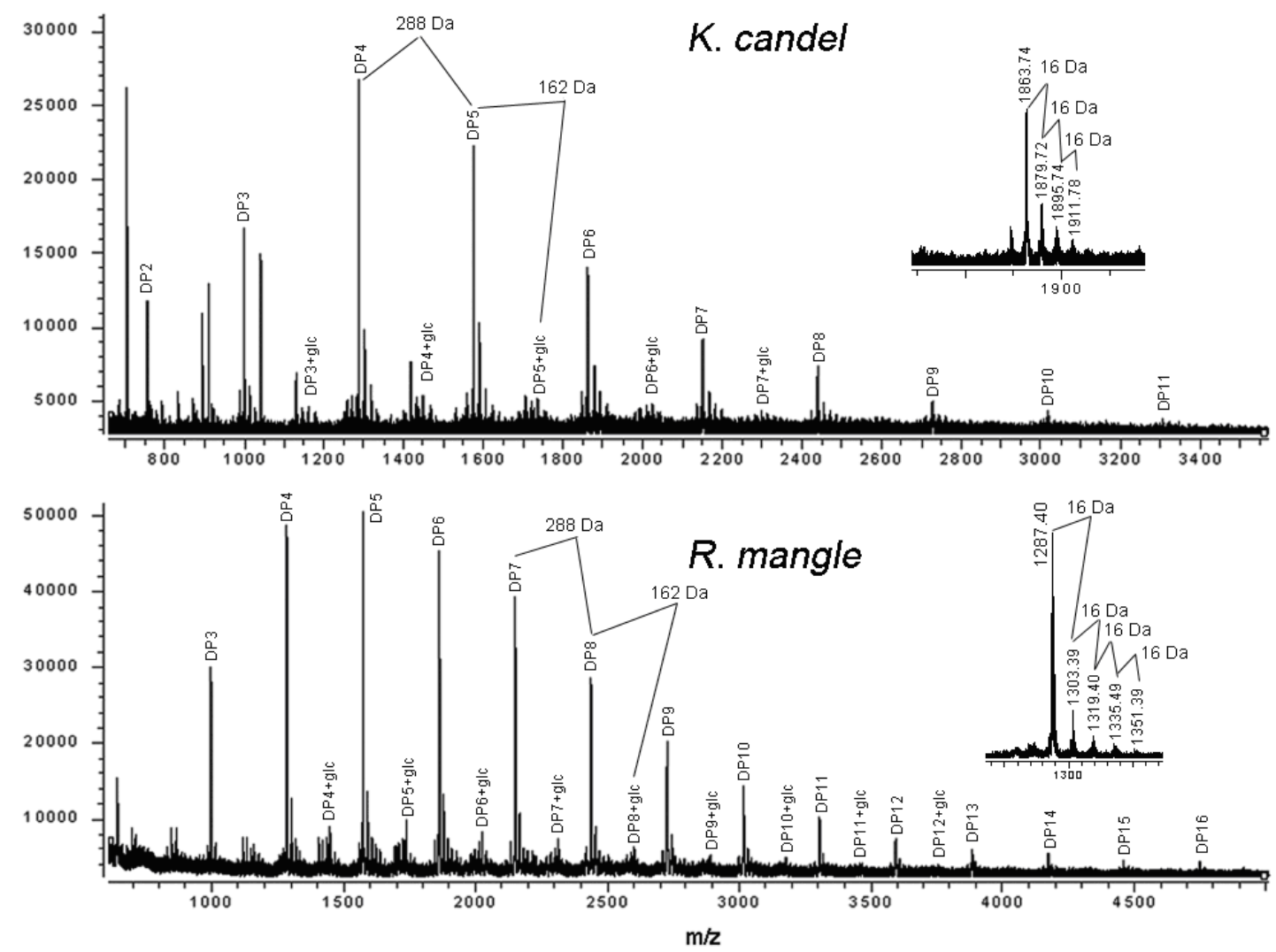

Table 2. Summary of peaks with the highest intensities in MALDI-TOF MS of the condensed tannins from $K$. candel and R. mangle.

\begin{tabular}{cccccc}
\hline Polymer & $\mathbf{n}_{\mathbf{1}}$ & $\mathbf{n}_{\mathbf{2}}$ & $\mathbf{n}_{\mathbf{3}}$ & $\boldsymbol{K}$. candel & $\boldsymbol{R}$. mangle \\
\hline DP2 & 2 & 0 & 0 & 711.33 & \\
\hline DP3 & 3 & 0 & 0 & 999.35 & 999.34 \\
& 3 & 0 & 1 & 1161.35 & \\
& 2 & 1 & 0 & 1015.37 & 1015.34 \\
& 1 & 2 & 0 & 1031.38 & \\
\hline DP4 & 4 & 0 & 0 & 1287.43 & 1287.40 \\
& 4 & 0 & 1 & 1449.44 & 1449.46 \\
& 3 & 1 & 0 & 1303.42 & 1303.39 \\
& 3 & 1 & 1 & & 1465.62 \\
\hline
\end{tabular}


Table 2. Cont.

\begin{tabular}{|c|c|c|c|c|c|}
\hline & 2 & 2 & 0 & 1319.41 & 1319.40 \\
\hline & 2 & 2 & 1 & & 1481.58 \\
\hline & 1 & 3 & 0 & & 1335.49 \\
\hline & 0 & 4 & 0 & & 1351.39 \\
\hline \multirow[t]{9}{*}{ DP5 } & 5 & 0 & 0 & 1575.57 & 1575.51 \\
\hline & 5 & 0 & 1 & 1737.71 & 1737.66 \\
\hline & 4 & 1 & 0 & 1591.59 & 1591.51 \\
\hline & 4 & 1 & 1 & & 1753.77 \\
\hline & 3 & 2 & 0 & 1607.56 & 1607.51 \\
\hline & 3 & 2 & 1 & & 1769.46 \\
\hline & 2 & 3 & 0 & & 1623.47 \\
\hline & 1 & 4 & 0 & & 1639.48 \\
\hline & 0 & 5 & 0 & & 1655.41 \\
\hline \multirow[t]{9}{*}{ DP6 } & 6 & 0 & 0 & 1863.74 & 1863.70 \\
\hline & 6 & 0 & 1 & 2025.87 & 2026.83 \\
\hline & 5 & 1 & 0 & 1879.72 & 1879.70 \\
\hline & 5 & 1 & 1 & & 2043.82 \\
\hline & 4 & 2 & 0 & 1895.74 & 1895.70 \\
\hline & 4 & 2 & 1 & & 2058.75 \\
\hline & 3 & 3 & 0 & 1911.78 & 1911.61 \\
\hline & 2 & 4 & 0 & & 1927.68 \\
\hline & 1 & 5 & 0 & & 1943.63 \\
\hline \multirow[t]{6}{*}{ DP7 } & 7 & 0 & 0 & 2151.97 & 2151.94 \\
\hline & 7 & 0 & 1 & 2314.98 & 2314.24 \\
\hline & 6 & 1 & 0 & 2167.97 & 2167.94 \\
\hline & 5 & 2 & 0 & 2183.99 & 2183.99 \\
\hline & 4 & 3 & 0 & & 2199.95 \\
\hline & 3 & 4 & 0 & & 2215.94 \\
\hline \multirow[t]{4}{*}{ DP8 } & 8 & 0 & 0 & 2439.39 & 2440.30 \\
\hline & 8 & 0 & 1 & & 2603.31 \\
\hline & 7 & 1 & 0 & 2456.38 & 2457.24 \\
\hline & 6 & 2 & 0 & & 2473.26 \\
\hline \multirow[t]{4}{*}{ DP9 } & 9 & 0 & 0 & 2727.79 & 2729.69 \\
\hline & 9 & 0 & 1 & & 2892.88 \\
\hline & 8 & 1 & 0 & 2744.93 & 2745.69 \\
\hline & 8 & 1 & 1 & & 3018.09 \\
\hline \multirow[t]{4}{*}{$\overline{D P 10}$} & 10 & 0 & 0 & 3016.09 & 3017.09 \\
\hline & 10 & 0 & 1 & & 3180.47 \\
\hline & 9 & 1 & 0 & & 3033.95 \\
\hline & 8 & 2 & 0 & & 3050.11 \\
\hline \multirow[t]{3}{*}{$\overline{\text { DP11 }}$} & 11 & 0 & 0 & 3304.45 & 3307.23 \\
\hline & 11 & 0 & 1 & & 3469.28 \\
\hline & 10 & 1 & 0 & & 3323.31 \\
\hline \multirow[t]{3}{*}{ DP12 } & 12 & 0 & 0 & & 3596.28 \\
\hline & 12 & 0 & 1 & & 3758.37 \\
\hline & 11 & 1 & 0 & & 3611.74 \\
\hline \multirow[t]{2}{*}{$\overline{\mathrm{DP} 13}$} & 13 & 0 & 0 & & 3884.89 \\
\hline & 12 & 1 & 0 & & 3899.78 \\
\hline DP14 & 14 & 0 & 0 & & 4173.27 \\
\hline DP15 & 15 & 0 & 0 & & 4463.13 \\
\hline DP16 & 16 & 0 & 0 & & 4751.54 \\
\hline
\end{tabular}

$n_{1}$ : Number of catechin unit; $n_{2}$ : Number of gallocatechin unit; $n_{3}$ : Number of glycoside. 
In addition to the predicted homopolyflavan-3-ol mass series mentioned above, each DP had a subset of masses 16, 32 and 48 Da higher (Figure 2 and Table 2). These masses can be explained by heteropolymers of repeating flavan-3-ol units containing an additional hydroxyl group $(\Delta 16 \mathrm{Da})$ at the position $5^{\prime}$ of the B-ring. Given the absolute masses corresponding to each peak, it was further suggested that they contain procyanidins and prodelphinidins, as have already been indicated in the ${ }^{13} \mathrm{C}-\mathrm{NMR}$ spectra. Each peak of the condensed tannins from studied mangrove species was always followed by mass signals at a distance of $162 \mathrm{Da}$ corresponding to the addition of one glycoside group at the heterocyclic C-ring. Thus, peak signals corresponding to glycosylated derivatives of various procyanidin oligomers were easily attributed. No procyanidins with more than one glycoside group were detected. Therefore, MALDI-TOF mass spectrometry indicated the simultaneous occurrence of a mixture of procyanidin polymers and monoglycosylated derivatives of procyanidin polymers, showing that there was a mixture of glycosylated procyanidins and procyanidins occurring in condensed tannin oligomers from $K$. candel and $R$. mangle leaves (Figure 2). These were consistent with the evidence found in ${ }^{13} \mathrm{C}$-NMR spectra. A previous study has identified two flavan-3-ol glycosides from stems of the mangrove plant $R$. stylosa [18]. The MALDI-TOF mass spectrometry has demonstrated the potential to rapidly analyze flavonol glycosides in a complex extract. The series of compounds with 2 Da multiples lower than those described peaks for heteropolyflavan-3-ols were not detected, so A-type interflavan ether linkage does not occur between adjacent flavan-3-ol subunits. The galloyl group which showed the mass signals at a distance of $152 \mathrm{Da}$ was not detected in the mass spectra although it has been reported in another mangrove species $R$. apiculata [19]. For the first time, compositional analysis of condensed tannins from mangrove species using MALDI-TOF MS and ${ }^{13} \mathrm{C}$-NMR have been successfully demonstrated.

The characterization of the condensed tannins was limited with respect to the detection of high mass condensed tannins and by the fact that peak intensities were not related to their concentration in the sample. The quality of the spectrum depended upon parameters such as the tannin/matrix ratio, the target area of the laser, and the crystallization of the mixture on the target. Therefore, it was very difficult to obtain a reproducible spectrum. The main problem is to find a new technique that permits the complete characterization of condensed tannins up to $4,000 \mathrm{Da}$, which allows an equal sensitivity for both low and high mass polymers.

\subsection{Free radical scavenging activity}

The relatively stable organic radical DPPH has been widely used in the determination of antioxidant activity of single compounds as well as the different plant extracts [20-25]. The reduction capacity of DPPH was determined by the decrease in its absorbance at $517 \mathrm{~nm}$, which is reduced by antioxidants [20]. The free radical scavenging activities of condensed tannins from $K$. candel and $R$. mangle along with the reference standards of ascorbic acid and BHA were determined by the DPPH assay. Because activities are expressed as the condensed tannins concentration required to achieving a $50 \%$ decrease in absorbance at $517 \mathrm{~nm}\left(\mathrm{IC}_{50}\right)$, the smaller condensed tannins concentration indicates the higher DPPH radical scavenging activity. Condensed tannins from two mangrove species all showed the significantly higher inhibition percent of DPPH radical compared to reference ascorbic acid and BHA. The $\mathrm{IC}_{50}$ values of condensed tannins from $R$. mangle and $K$. candel were $89.83 \pm 4.91 \mu \mathrm{g} / \mathrm{mL}$ and 
$93.51 \pm 4.44 \mu \mathrm{g} / \mathrm{mL}$ respectively $(P>0.05)$. It was reported that the glycoside moiety in condensed tannins structure can enhance the effectiveness of condensed tannins radical scavenging [18]. Figure 3A shows the DPPH free radical scavenging activity of the studied condensed tannins and the references at different concentrations, and demonstrated that all of the tested antioxidants showed dose-dependent activity. The free radical scavenging activity increased with the increasing concentration of condensed tannins.

\subsection{Reducing antioxidant power}

The reduction capacity of a compound may serve as a significant indicator of its potential antioxidant activity [26]. A higher absorbance corresponds to a higher ferric reducing power. For each antioxidant, different concentrations $(0.01-0.5 \mathrm{mg} / \mathrm{mL})$ were prepared. All condensed tannins showed increased ferric reducing power with the increasing concentration $(0-0.5 \mathrm{mg} / \mathrm{mL})$ (Figure $3 \mathrm{~B})$. In accordance with the findings from the DPPH assay, the reducing power of the condensed tannins from R. mangle $(12.98 \pm 1.20 \mathrm{mmol}$ AAE/g) was superior to that of $K$. candel $(10.77 \pm 0.37 \mathrm{mmol} \mathrm{AAE} / \mathrm{g})$, $\mathrm{BHA}(4.19 \pm 0.11 \mathrm{mmol} \mathrm{AAE} / \mathrm{g})$ and $(3.89 \pm 0.12 \mathrm{mmol} \mathrm{AAE} / \mathrm{g})$.

Figure 3. DPPH radical scavenging activity (A) and reducing power (B) of RMCT, KCCT and reference standards at different concentration. RMCT and KCCT were respective condensed tannins from $R$. mangle and $K$. candel.
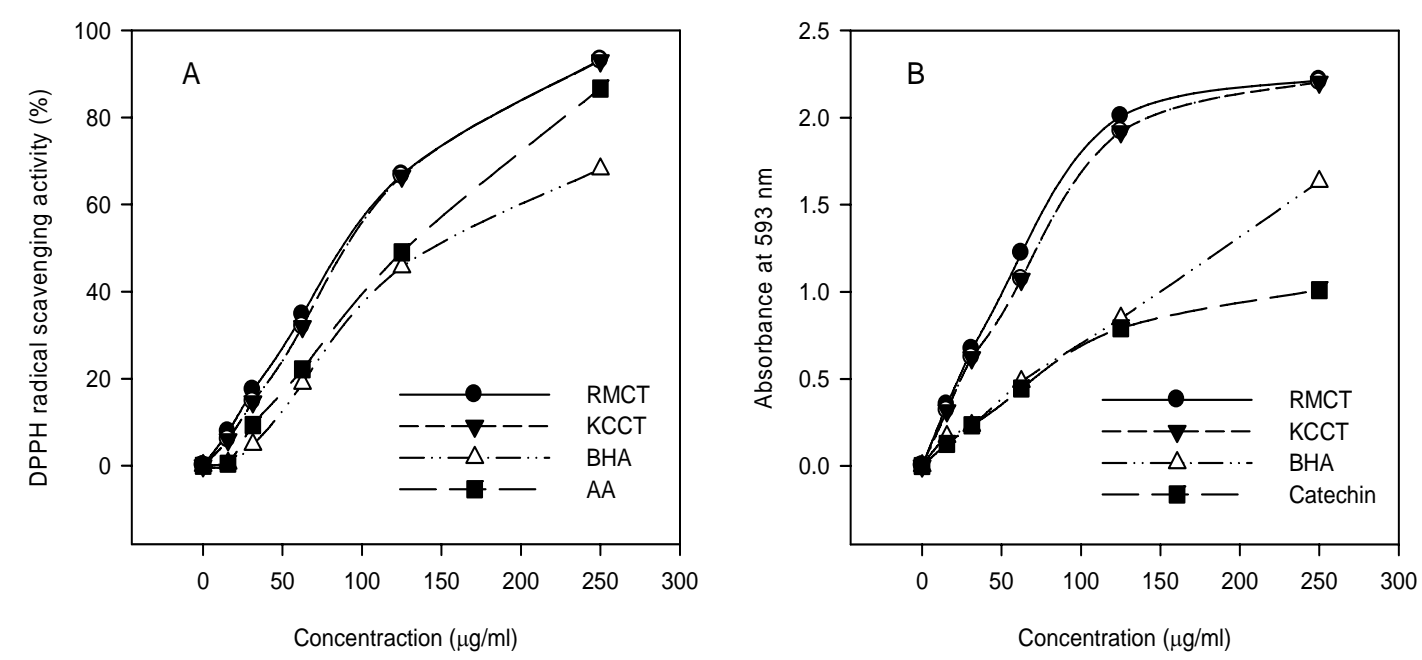

\section{Experimental}

\subsection{Chemicals and plant materials}

All solvents used were of analytical reagent (AR) purity grade. Ascorbic acid (AA), butylated hydroxyanisole (BHA), tannic acid, catechin, TPTZ (2,4,6-tripyridyl-S-triazine) and DPPH (1,1diphenyl-2-picrylhydrazyl) were purchased from Sigma-Aldrich (USA). Sephadex LH-20 was purchased from Amersham (USA). The mangrove species $K$. candel and R. mangle were collected from a mangrove forest in the Dongzhai harbor $\left(19^{\circ} 56^{\prime} \mathrm{N}, 110^{\circ} 34^{\prime} \mathrm{E}\right)$, Hainan, China. $R$. mangle was introduced from La Paz and Mazatlan City, Mexico in 1999 [27]. 


\subsection{Extraction and purification of condensed tannins}

Leaf samples were taken to the laboratory immediately after collection and cleaned with distilled water. The condensed tannins were extracted and purified as described by Lin et al. [28]. The condensed tannins were freeze-dried and stored at $-20{ }^{\circ} \mathrm{C}$ before analysis by ${ }^{13} \mathrm{C}-\mathrm{NMR}$ and MALDITOF mass spectrometry.

\subsection{Determination of total phenolics and extractable condensed tannins}

Total phenolics and extractable condensed tannins of raw extracts of the leaves were determined. Total phenolics were measured with the Prussian Blue method [29], using tannic acid as the standard. Extractable condensed tannins were assayed by the butanol- $\mathrm{HCl}$ method [30], using purified condensed tannins from respective mangrove species as the standards.

\section{4. ${ }^{13} \mathrm{C}-\mathrm{NMR}$ analysis}

The ${ }^{13} \mathrm{C}$-NMR spectra of condensed tannins were recorded on Varian Metcury-600 spectrometer (USA) at $150 \mathrm{MHz}$. The samples for recording NMR spectra were prepared by dissolving the samples in acetone- $d_{6} / \mathrm{D}_{2} \mathrm{O}$ mixture.

\subsection{MALDI-TOF MS analysis}

The MALDI-TOF mass spectra were recorded on a Bruker Reflex III MALDI-TOF mass spectrometer (Germany). The irradiation source was a pulsed nitrogen laser with a wavelength of $337 \mathrm{~nm}$, and the duration of the laser pulse was $3 \mathrm{~ns}$. The measurements were carried out using the following conditions: in the positive ion mode, an accelerating voltage of $20.0 \mathrm{kV}$ and a reflectron voltage of $23.0 \mathrm{kV}$ were used. Cesium chloride and 2,5-dihydroxybenzoic acid (DHB) as the matrix were used to enhance ion formation. Amberlite IRP-64 cation-exchange resin (Sigma-Aldrich), equilibrated in deionized water, was used to deionize the analyte/matrix solution thrice. An aqueous solution of cesium chloride $(0.5 \mu \mathrm{L}, 1 \mathrm{mg} / \mathrm{mL})$ was added to the sample solution $(1.5 \mu \mathrm{L}, 10 \mathrm{mg} / \mathrm{mL}$ aqueous) followed by addition of an equal volume of DHB (10 mg/mL aqueous solution). The resulting solution $(1.0 \mu \mathrm{L})$ was evaporated and introduced into the mass spectrometer [31].

\subsection{DPPH radical scavenging activity}

To assess the scavenging ability on DPPH radicals, condensed tannins $(0.1 \mathrm{~mL}, 15-250 \mu \mathrm{g} / \mathrm{mL})$ in methanol were mixed with $3 \mathrm{~mL}$ of methanol solution containing DPPH radicals $(0.004 \%$, w/w). The mixture was shaken vigorously and left to stand for $30 \mathrm{~min}$ in the dark before measuring the absorbance at $517 \mathrm{~nm}$ against a blank [22]. Ascorbic acid and BHA were used as reference standards. Then the scavenging ability was calculated as:

Scavenging ability $(\%)=\left[\left(\Delta A_{517}\right.\right.$ of control $-\Delta A_{517}$ of sample $) / \Delta A_{517}$ of control $] \times 100$ 


\subsection{Reducing antioxidant power effects}

Reducing power antioxidant effects were determined following the method by Benzie and Strain [32]. Briefly, FRAP reagent $(3 \mathrm{~mL})$, prepared freshly, was mixed with test sample $(0.1 \mathrm{~mL})$, or methanol (for the reagent blank). The FRAP reagent contained $10 \mathrm{mM}$ TPTZ solution $(2.5 \mathrm{~mL})$ in $40 \mathrm{mM} \mathrm{HCl}$ plus $20 \mathrm{mM} \mathrm{FeCl}_{3}(2.5 \mathrm{~mL})$ and $0.3 \mathrm{M}$ acetate buffer, $\mathrm{pH} 3.6(25 \mathrm{~mL})$. The absorbance of reaction mixture was measured spectrophotometrically at $593 \mathrm{~nm}$ after incubation at $25{ }^{\circ} \mathrm{C}$ for 10 min. The FRAP values, expressed in mmol ascorbic acid equivalent (AAE)/g sample in dry weight were derived from a standard curve, and BHA and catechin were used as reference standards.

\subsection{Statistical analysis}

All measurements were replicated three times and a one-way ANOVA test was performed on the antioxidant activity results to investigate significant differences between two mangrove species. The method used to discriminate among the means was Duncan's multiple range tests. The computer program employed was SPSS 11.0 for Windows.

\section{Conclusions}

Structures of condensed tannins from two mangrove species, $R$. mangle and $K$. candel characterized by ${ }^{13} \mathrm{C}$-NMR and MALDI-TOF MS analyses showed that the condensed tannins consisted of predominantly procyanidins with 2,3-cis stereochemistry. There are some of monoglycoside flavan-3ols polymers with polymerization degree up to 12 were detected in mass spectra of mangrove species. Condensed tannins extracted from two mangrove species showed very good DPPH radical scavenging activity and ferric reducing power.

\section{Acknowledgements}

This research work was supported by Program for New Century Excellent Talents in University (NCET-07-0725) and by Program for Innovative Research Team in Science and Technology in Fujian Province University.

\section{References}

1. Hemingway, R.W.; Karchesy, J.J. Chemistry and Significance of Condensed Tannins; Plenum: New York, NY, USA, 1989.

2. Porter, L.J. The Flavonoids, Advances in Research Since 1980; Harborne, J.B., Ed.; Chapman and Hall: New York, NY, USA, 1988; p. 21.

3. Hemingway, R.W.; Laks, P.E. Plant Polyphenols 1: Synthesis, Properties, Significance; Plenum: New York, NY, USA, 1992.

4. Saito, M.; Hosoyama, H.; Ariga, T.; Kataoka, S.; Yamaji, N.J. Antiulcer activity of grape seed extract and procyanidins. J. Agric. Food Chem. 1998, 46, 1460-1464.

5. Feller, I.C.; Whigham, D.; O’Neill, J.; McKee, K. Effects of nutrient enrichment on within-stand cycling in a mangrove forest. Ecology 1999, 80, 2193-2205. 
6. Hernes, P.J.; Benner, R.; Cowie, G.L.; Goni, M.A.; Bergamaschi, B.A.; Hedges, J.I. Tannin diagenesis in mangrove leaves from a tropical estuary: A novel molecular approach. Geochim. Cosmochim. Acta. 2001, 65, 3109-3122.

7. Mainoya, J.; Mesaki, S.; Banyikwa, F.F. The distribution and socio-economic aspects of mangrove forests in Tanzania. In Man in the Mangroves: the Socio-Economic Situation of Human Settlements in Mangrove Forests; Kunstadter, P.E., Bird, C.F., Sabhasri, S., Eds.; United Nations University: Tokyo, Japan, 1986; pp. 87-95.

8. Pittier, H. Manual de las plantas usuales de Venezuela; Fundación Eugenio Mendoza: Caracas, Venezuela, 1978.

9. Lemmens, R.; Wilijarni-Soetjipto, N. Dye and tannin-producing plants. Pudoc: Wageningen, The Netherlands, 1991.

10. Banerjee, D.; Chakrabarti, S.; Hazra, A.K.; Banerjee, S.; Ray, J.; Mukherjee, B. Antioxidant activity and total phenolics of some mangroves in Sundarbans. Afr. J. Biotechnol. 2008, 7, 805-810.

11. Rahim, A.A.; Rocca, E.; Steinmetz, J.; Kassim, M.J.; Sani-Ibrahim, M.; Osman, H. Antioxidant activity of mangrove Rhizophora apiculata bark extracts. Food Chem. 2008, 107, 200-207.

12. Rahim, A.A.; Rocca, E.; Steinmetz, J.; Kassim, M.J; Adnan, R.; Sani-Ibrahim, M. Mangrove tannins and their flavanoid monomers as alternative steel corrosion inhibitors in acidic medium. Corros. Sci. 2007, 49, 402-417.

13. Pasch, H.; Pizzi, A.; Rode, K. MALDI-TOF mass spectrometry of polyflavonoid tannins. Polymer 2001, 42, 7531-7539.

14. Dixon, R.A.; Xie, D.Y.; Sharma, S.B. Proanthocyanidins - A final frontier in flavonoid research. New Phytol. 2005,165, 9-28.

15. Czochanska, Z.; Foo, L.Y.; Newman, R.H.; Porter, L.J. Polymeric proanthocyanidins. Stereochemistry, structural units and molecular weight. J. Chem. Soc., Perkin Trans. 1980, 1, 2278-2286.

16. Shoji, T.; Mutsuga, M.; Nakamura, T.; Kanda, T.; Akiyama, H.; Goda, Y. Isolation and structural elucidation of some procyanidins from apple by low temperature nuclear magnetic resonance. $J$. Agric. Food Chem. 2003, 51, 3806-3813.

17. Castillo-Munoz, N.; Gomez-Alonso, S.; Garcia-Romero, E.; Gomez, M.; Velders, A.; HermosinGutierrez, I. Flavonol 3-O-glycosides series of Vitis vinifera cv. petit verdot red wine grapes. $J$. Agric. Food Chem. 2008, 57, 209-219.

18. Takara, K.; Kuniyoshi, A.; Wada, K.; Kinjyo, K.; Iwasaki, H. Antioxidative flavan-3-ol glycosides from stems of Rhizophora stylosa. Bios. Biotechnol. Biochem. 2008, 72, 2191-2194.

19. Oo, C.W.; Pizzi, A.; Pasch, H.; Kassim, M.J. Study on the structure of mangrove polyflavonoid tannins with MALDI-TOF mass spectrometry. J. Appl. Polym. Sci. 2008, 109, 963-967.

20. Duh, P.D.; Tu, Y.Y.; Yen, G.C. Antioxidant activity of water extract of Harng Jyur (Chrysanthemum morifolium Ramat). Leb-ensm. Wiss. Technol. 1999, 32, 269-277.

21. Fukumoto, L.R.; Mazza, G. Assessing antioxidant and prooxidant activities of phenolic compounds. J. Agric. Food Chem. 2000, 48, 3597-3604.

22. Braca, A.; Tommasi, N.D.; Bari, L.D.; Pizza, C.; Politi, M.; Morelli, I. Antioxidant principles from Bauhinia terapotensis. J. Nat. Prod. 2001, 64, 892-895. 
23. Zheng, W.; Wang, S.Y. Antioxidant activity and phenolic compounds in selected herbs. J. Agric. Food Chem. 2001, 49, 5165-5170.

24. Zhang, L.L.; Lin, Y.M. HPLC, NMR and MALDI-TOF MS analysis of condensed tannins from Lithocarpus glaber leaves with potent free radical scavenging activity. Molecules 2008, 13, 2986-2997.

25. Zhang, L.L.; Lin, Y.M. Antioxidant tannins from Syzygium cumini fruit. Afr. J. Biotechnol. 2009, 8, 2301-2309.

26. Meir, S.; Kanner, J.; Akiri, B.; Hadas, S.P. Determination and involvement of aqueous reducing compounds in oxidative defense systems of various senescing leaves. J. Agric. Food Chem. 1995, 43, 1813-1815.

27. Liao, B.W.; Zheng, S.F.; Chen, Y.J.; Li, M.; Zeng, W.J.; Zheng, D.Z. Preliminary report on introduction of several alien mangrove plants in Dongzhai harbor of Hainan island China. J. Cent S. For. Uni. 2006, 26, 63-67.

28. Lin, Y.M.; Liu, J.W.; Xiang, P.; Lin, P.; Ye, G.F.; Sternberg, L.DSL. Tannin dynamics of propagules and leaves of Kandelia candel and Bruguiera gymnorrhiza in the Jiulong River Estuary, Fujian, China. Biogeochemistry 2006, 78, 343-359.

29. Graham, H.D. Stabilization of the Prussian blue color in the determination of polyphenols. $J$. Agric. Food Chem. 1992, 40, 801-805.

30. Terrill, T.H.; Rowan, A.M.; Douglas, G.B.; Barry, T.N. Determination of extractable and bound condensed tannin concentrations in forage plants, protein concentrate meals and cereal grains. $J$. Sci. Food Agric. 1992, 58, 321-329.

31. Xiang, P.; Lin, Y.M.; Lin, P.; Xiang, C. Effects of adduct ions on matrix-assisted laser desorption/ionization time of flight mass spectrometry of condensed tannins: A prerequisite knowledge. Chin. J. Anal. Chem. 2006, 34, 1019-1022.

32. Benzie, I.F.F.; Strain, J.J. The ferric reducing ability of plasma (FRAP) as a measure of "antioxidant power": The FRAP assay. Anal. Biochem. 1996, 239, 70-76.

Sample Availability: Samples of the compounds are available from the authors.

(C) 2010 by the authors; licensee Molecular Diversity Preservation International, Basel, Switzerland. This article is an open-access article distributed under the terms and conditions of the Creative Commons Attribution license (http://creativecommons.org/licenses/by/3.0/). 